\title{
INTERSECTIONS Between the Academy and Practice Collaboration: Technology, Reserach, Practice
}

\author{
SYMPOSIUM CO-CHAIRS \\ John Folan, Carnegie Mellon University \\ Julie Ju-Youn Kim, Georgia Institute of Technology
}

\section{INTRODUCTION}

The content included in this volume provides several demonstrable models for how the architectural academy and practice might intersect with greater efficacy and frequency. The writing is unilaterally optimistic - not because it is speculative, but rather because it chronicles processes and methods that have been tested in application. While presented through a set of distinct lenses, all of the work reinforces the underlying positive sensibility inherent in collaboration - collective intelligence. Diverse in scale, scope, and focus, each offers critical assessment of applied knowledge gained through experience. Simultaneously, while diverse, each communicates strategies that are transferrable across those same platform boundaries. In several cases, the work and methodologies chronicled are retroactive in nature, examining the DNA of a building process; oriented toward scientific analysis of how collaborative process might have yielded better performance. In others, the work illustrates alternative models of practice and project team building that can enhance ecological resilience. All of the topics addressed by the authors are timely, relevant to contemporary architectural education and practice, and have been curated to illuminate potential.

Writing about material investigations and industry research collaborations most directly identifies areas for concern that will need to be addressed as the academy and practice seek more opportunities to intersect. Several questions emerge. What are the implications to academic freedom when funding is tied to performance based deliverables? What are the implications to pedagogy necessary for fundamental skill development? With universities and schools of architecture under increasing pressure to offset capital and operational costs, what are the best models of professional/academic collaboration that will ensure ethical constancy within both realms? Issues identified in these proceedings set the table for necessary discourse and seek to perpetuate the relevance of future Intersections Symposia.

As co-chairs of this Intersections symposium, we would be remiss if we did not recognize the efforts of our predecessors. The success in attracting the quality of papers included here across the domains of technology, research and practice is evidence of an inherited legacy and forum for discourse. Without the support of the American Institute of Architects and Association of Collegiate Schools of Architecture, and their foresight in providing a platform for this exchange, the work of everyone represented in these proceedings would not be possible. We would like to express our personal gratitude to co-conspirators in the production of this volume, Eric Wayne Ellis, ACSA Director of Operations and Programs, Ming Hu, former AIA Director of Academic Engagement, and Nissa DahlinBrown, present AIA Director of Academic Engagement. Without their efforts, the diversity and scope of what is discussed would not have been as broad or focused in setting the stage for future Intersections Symposia. As with the content represented in this volume, the work in preparation was and is the result of our collaboration with many others.

-John Folan and Julie Ju-Youn Kim, Co-Chairs 